\title{
Biochemical characterization of a functional recombinant aryl-alcohol dehydrogenase from Taiwanofungus camphorata
}

\author{
Chuian-Fu Ken ${ }^{2 \dagger}$, Che-Chi Chang ${ }^{1 \dagger}$, Lisa Wen ${ }^{3 \dagger}$, Jenq-Kuen Huang ${ }^{3 \dagger}$ and Chi-Tsai Lin ${ }^{1 *}$
}

\begin{abstract}
Background: Aryl-alcohol dehydrogenases (AADs) have been known to involve in the metabolism of aromatic compounds.

Results: One TCAAD cDNA (GenBank HQ453361) encoding a putative aryl-alcohol dehydrogenase (AAD) was cloned from Taiwanofungus camphorata. The deduced amino acid sequence is conserved among the reported AADs. A 3-D structural model of the TCAAD has been created based on the known structure of voltage-dependent potassium channels subunit beta-2 (PDB code: 3EAU). To characterize the TCAAD, the coding region was subcloned into an expression vector and transformed into Saccharomyces cerevisiae. The recombinant His6-tagged TcAAD was overexpressed and purified by Ni affinity chromatography. The purified enzyme showed a band of approximately $39 \mathrm{kDa}$ on a $12 \%$ SDS-PAGE. The molecular mass determined by MALDI-TOF is $40.58 \mathrm{kDa}$ which suggests that the purified enzyme is a monomeric enzyme. Using veratraldehyde as a substrate, the $K_{\mathrm{M}}, V_{\max }$ of TcADD was determined at $\mathrm{pH}$ 6.0. Using benzyl alcohol derivatives as substrates, the oxidizing power of TCADD via NAD ${ }^{+}$at pH 9.6 was studied.
\end{abstract}

Conclusions: The coding sequence of the TCAAD CDNA was introduced into an S. cerevisiae expression system and the active enzyme purified and characterized. Understanding the properties of this TCAAD will be beneficial for its potential in xenobiotic detoxification or production of natural flavors.

Keywords: Taiwanofungus camphorata; Aryl-alcohol dehydrogenase; Three-dimension structural model (3-D structural model); Veratraldehyde; 3, 4-Dimethoxybenzyl alcohol; 2, 4-Dimethoxybenzyl alcohol

\section{Background}

Taiwanofungus camphorata (T. camphorata, formerly named Antrodia camphorata) is a high valued mushroom found only in the forests of Taiwan. It has been used for centuries as health food and drug intoxication, among others (Ao et al., 2009). T. camphorata has been shown to exhibit anti-inflammatory properties (Hsieh et al., 2010). The compounds identified from the fruiting bodies or mycelia of $T$. camphorata in a submerged culture are benzenoids, diterpenes, maleic and succinic acid derivatives, polysaccharides, steroids, and triterpenoids

\footnotetext{
* Correspondence: B0220@mail.ntou.edu.tw

${ }^{\dagger}$ Equal contributors

'Institute of Bioscience and Biotechnology and Center of Excellence for the Oceans, National Taiwan Ocean University, 2 Pei-Ning Road, Keelung 202, Taiwan

Full list of author information is available at the end of the article
}

(Ao et al., 2009). A lot of studies were aimed to find the exact bioactive compounds of the mushroom (Ao et al., 2009). In order to search for physiologically active components including antioxidant enzymes, we have established an expressed sequence tag (EST) from the fruiting bodies of $T$. camphorata. Based on the established EST, several antioxidant enzymes including a superoxide dismutase (Liau et al., 2007), a 1-Cys peroxiredoxin (Wen et al. 2007), a catalase (Ken et al., 2008), a glutathione formaldehyde dehydrogenase (Huang et al., 2009), a dithiol glutaredoxin (Ken et al., 2009), a 2-Cys peroxiredoxin isozyme (Liau et al., 2010) and a monothiol glutaredoxin (Ken et al., 2011) have been cloned and characterized. This encourages us further to search for active components from the established EST of T. camphorata for potential health food applications. 
Aryl-alcohol dehydrogenases (AADs) have been known to involve in the metabolism of aromatic compounds (Muheim et al., 1991). Fungal AADs are also believed to be involved in the biosynthesis of veratryl alcohol as a secondary metabolite by white-rot fungi (Jensen et al., 1994; Yang et al., 2012). The glycosylation reaction is one of the major fungal reactions for xenobiotic detoxification (Jensen et al., 1994) and the formation of hydroxymethyl group is essential for glycosylation reactions. AAD may play an important role in maintaining a hydroxymethyl group under oxidative circumstances for effective xylosylation reaction (Ichinose et al., 1999; Ichinose et al., 2002) on the microbial production of natural flavors and fragrances such as the rose-like flavor compound of 2-phenylethanol (Yang et al., 2012).

Here, we report the cloning, expression and purification of a functional recombinant TcAAD from T. camphorata for biochemical characterization. The mature coding sequence of the TcAAD cDNA was introduced into an $S$. cerevisiae expression system and the resulting active enzyme was purified and characterized. Understanding the properties of this TcAAD will be beneficial for its potential in xenobiotic detoxification or production of natural flavors.

\section{Methods}

Total RNA preparation from $T$. camphorata and CDNA synthesis

Fruiting bodies of T. camphorata, a fungus that occurs only in the inner cavity of an endangered tree Cinnamonum kanehirai, were obtained from Asian Nova Biotechnology Inc, Taiwan (http://www.asian-bio.com/). Fresh fruiting bodies (wet weight $10 \mathrm{~g}$ ) were frozen in liquid nitrogen and ground to powder in a ceramic mortar. PolyA mRNA (25 $\mu \mathrm{g}$ ) was prepared using Novagen's Straight A's mRNA Isolation System (Gibbstown, NJ, USA). Four micrograms of the mRNA were used in the $5^{\prime}$-RACEReady cDNA and 3'-RACE-Ready cDNA synthesis using Clontech's SMART RACE cDNA Amplification Kit (Mountain View, CA).

\section{Isolation of TCAAD CDNA}

We have previously established an EST database from fruiting bodies of $T$. camphorata and sequenced all clones with insert size greater than $0.4 \mathrm{~kb}$ (data not shown). The identity of a partial AAD cDNA clone was assigned by comparing the inferred amino acid sequence in various databases using the basic local alignment search tool (BLAST) (http://www.ncbi.nlm.nih.gov/blast/ Blast.cgi). Using the $T$. camphorata 5'-RACE-Ready cDNA as a template, an UPM primer (universal primer A mix, purchased from BD Biosciences, Palo Alto, CA) and a primer (5'GAT ATT CCA CTC GGC CTT GAC C3' ) based on AAD partial cDNA, a 700 bp fragment was amplified by PCR. The 700 bp fragment was subsequently subcloned and sequenced. Based on the DNA sequence, a reverse primer AAD-1 (5' CCT CTC GAG GGA GAT TCA A 3') and a forward primer AAD-2 (5' GAG GTG ATG CTG GGG AAT3') were synthesized. Using the $T$. camphorata 5'-RACE-Ready cDNA as a template and AAD-1 and UPM primer pair, a 400 bp fragment was amplified by PCR. Using the T. camphorata 3'-RACE-Ready cDNA as a template and AAD-2 and UPM primer pair, a 1,200 bp fragment was amplified by PCR. Both DNA fragments were subcloned into pCR4.0 vector and transformed into $E$. coli TOPO10, separately. The nucleotide sequence of the inserts was determined in both strands. Sequence analysis revealed that the combined sequences (400, 700 and 1,200 bp) covered an open reading frame of a putative AAD cDNA (1299 bp, GenBank no. HQ453361). The identity of this TcAAD clone was assigned by comparing the inferred amino acid sequence in various databases using the basic local alignment search tool (BLAST).

\section{Bioinformatics analysis of TCAAD}

The BLAST program was used to search homologous protein sequences in the nonredundant database (NRDB) at the National Center for Biotechnology Information, National Institutes of Health (http://www.ncbi.nlm.nih. gov/). Multiple alignments were constructed using ClustalW2 program. Protein secondary structure was predicted by SWISS-MODEL program and represented as $\alpha$ helices and $\beta$ strands. A 3-D structural model of TcAAD was created by SWISS-MODEL (Arnold et al., 2006) (http://swissmodel.expasy.org/) based on the known crystal structure of voltage-dependent potassium channels (PDB code:3EAU).

\section{Subcloning of TCAAD CDNA into an $E$. coli and yeast expression vector}

The coding region of the TcAAD cDNA was amplified using gene specific flanking primers. The $5^{\prime}$ upstream primer contains Eco RI recognition site (5'GAA TTC GAT GTC CGT GGA GAA GAA GTC3') and the 3' downstream primer contains Hind III recognition site (5'AAG CTT AGA ATG GCC ATC GGC CAA C 3'). Using $0.2 \mu \mathrm{g}$ of TcAAD cDNA as a template, and 10 pmole of each $5^{\prime}$ upstream and 3 ' downstream primers, a $1,044 \mathrm{bp}$ fragment encoding the putative mature TcAAD gene was amplified by PCR, and was ligated with cloning vector pCR4.0 and transformed into E. coli. The plasmid was isolated and digested with Eco RI and Hind III. The digestion products were separated on a $1.0 \%$ agarose gel. The 1,044 bp insert DNA was gel purified and subcloned into Eco RI and Hind III site of pET-20b(+) expression vector (Novagen, Darmstadt, Germany). The recombinant DNA was then transformed 
into E. coli C43(DE3). The recombinant protein was not overexpressed in the E. coli expression system.

Therefore the TcAAD gene was subcloned into a yeast expression system for overexpression. The coding region of the TcAAD cDNA was re-amplified by using two gene-specific primers: the $5^{\prime}$ upstream primer contains Eco RI recognition site (5'GAA TTC GAT GTC CGT GGA GAA GAA GTC3') whereas the 3' downstream primer contained a His6-tag and Eco RI recognition site (5' CGT CTC GAA TTC TCA GTG GTG GTG GTG GTG GTG 3'). Using the $0.2 \mu \mathrm{g}$ recombinant DNA of pET-20b(+)-TcAAD as a template, and 10 pmole of each $5^{\prime}$ upstream and 3' downstream primers, a $1.0 \mathrm{~kb}$ fragment was amplified by PCR. The fragment was ligated into pCR4.0 and transformed into E. coli. The recombinant plasmid was isolated and digested with Eco RI. The digestion products were separated on a $1.0 \%$ agarose gel. The $1.0 \mathrm{~kb}$ insert DNA was gel purified and subcloned into the Eco RI site of the pYEX-S1 expression vector (Clontech, Mountain View, CA, USA) and introduced into Saccharomyces cerevisiae (trp- $\left.\mathrm{ura}^{-}\right)$. The transformed yeast cells were selected by YNBDT $(0.17 \%$ yeast nitrogen base, $0.5 \%$ ammonium sulfate, and $2 \%$ glucose) agar plates containing $20 \mu \mathrm{g} \operatorname{Trp} / \mathrm{mL}$. The presence of TcAAD gene in the selected transformants was verified by PCR using gene-specific flanking primers. The recombinant TcAAD protein was expressed in yeast in YPD medium ( $1 \%$ yeast extract, $2 \%$ peptone, $2 \%$ glucose). Overexpression of the functional recombinant TcAAD was analyzed by enzyme activity assay.

\section{Expression and purification of the recombinant TCAAD}

The yeast transformant which containing the TcAAD gene was grown at $30^{\circ} \mathrm{C}, 170 \mathrm{rpm}$ in $250 \mathrm{~mL}$ of YPD medium for 2 days. The cells were harvested and the soluble proteins extracted in PBS (phosphate buffer saline) with glass beads as described previously (Ken et al., 2006). The recombinant TcAAD was purified by NiNTA affinity chromatography (elution buffer: 30\% PBS containing 20-250 $\mathrm{mM}$ imidazole) according to manufacturer's instruction (Qiagen). The purified protein was analyzed by a $12 \%$ SDS-PAGE followed by staining with Coomassie Brilliant Blue R-250 and destaining. Protein concentration was determined by a Bio-Rad Protein Assay Kit (Richmond, CA) using bovine serum albumin as a standard (Bradford, 1976).

\section{Molecular mass analysis via JOEL MALDI-TOF (JMS-S3000, Japan)}

The purified recombinant TcAAD $(1 \mathrm{mg} / \mathrm{mL})$ was dissolved in $0.3 \%$ PBS containing $0.05 \mathrm{mM}$ imidazole and $0.45 \%$ glycerol. The sample $(5 \mu \mathrm{L})$ was used for molecular mass determination using JOEL MALDI-TOF.

\section{TcAAD activity assay}

The AAD activity was determined by measuring NADPHdependent reduction of veratraldehyde (3,4-dimethoxybenzaldehyde, $\left(\mathrm{CH}_{3} \mathrm{O}\right)_{2} \mathrm{C}_{6} \mathrm{H}_{3} \mathrm{CHO}$ ) at $\mathrm{pH}$ 6.0 (Muheim et al., 1991; Guillen and Evans, 1994). A typical $100 \mu \mathrm{L}$ reaction mixture contained $25 \mathrm{mM}$ bis-tris- propane/ $\mathrm{HCl}$ ( $\mathrm{pH}$ 6.0), $0.2 \mathrm{mM} \mathrm{NADPH}$ and $0.2 \mathrm{mM}$ veratraldehyde. The reaction was initiated by addition of $3 \mu \mathrm{g}$ TcAAD. The reaction was followed by a decrease in $A_{365}$ due to the oxidation of NADPH. $\mathrm{A}_{365}$ was used instead of $\mathrm{A}_{340}$ to reduce the interferences with the maximum absorbance of veratraldehyde at $\mathrm{A}_{310}$ (Guillen and Evans, 1994). Under the same conditions, another set of reactions was set up except that NADPH was replaced with NADH for enzyme activity assay. The molar absorption coefficient of NADH at $355 \mathrm{~nm}$ is $4390 \mathrm{M}^{-1} \mathrm{~cm}^{-1}$.

The ability of the TcAAD to oxidize benzyl alcohols (benzyl alcohol; 2,4-dimethoxy benzyl alcohol; 3,4dimethoxybenzyl alcohol and 4-(hydroxymethyl)benzoic acid) was tested by measuring $\mathrm{NAD}^{+}$-dependent oxidation of these benzyl alcohols to their corresponding benzylaldehydes by increasing the production of NADH at $\mathrm{A}_{355} \mathrm{~nm}$. A typical $100 \mu \mathrm{L}$ reaction mixture contained $50 \mathrm{mM}$ glycine/ $\mathrm{NaOH}\left(\mathrm{pH}\right.$ 9.6), $4 \mathrm{mM} \mathrm{NAD}^{+}$and $4 \mathrm{mM}$ benzyl alcohols (Siljegovic et al., 1998). The reaction was initiated by addition of $10 \mu \mathrm{g}$ TcAAD. The reaction was followed by an increase in $A_{355}$ due to the reduction of $\mathrm{NAD}^{+}$. Under the same conditions, another set of reactions was set up except for $\mathrm{NAD}^{+}$was replaced with $\mathrm{NADP}^{+}$for enzyme activity assay.

\section{Kinetic studies}

The kinetic properties of the TcAAD $(3 \mu \mathrm{g})$ was determined by varying the concentrations of veratraldehyde (0.1 to $0.4 \mathrm{mM}$ ) with fixed amount of $0.2 \mathrm{mM}$ NADPH. The change in absorbance at $365 \mathrm{~nm}$ was recorded for one min. The molar absorption coefficient of NADPH at $365 \mathrm{~nm}$ is $3.5 \mathrm{mM}^{-1} \mathrm{~cm}^{-1}$. The $K_{\mathrm{M}}, \mathrm{V}_{\max }$ and $k_{\text {cat }}$ were calculated from Lineweaver-Burk plots.

\section{Enzyme characterization}

The TcAAD enzyme was tested for stability in terms of its activity under various conditions. Aliquots of the TcAAD sample were treated as follows: (1) Thermal effect. Each enzyme sample $(3 \mu \mathrm{g} / 12 \mu \mathrm{L})$ was heated to $58^{\circ} \mathrm{C}$ for $2,4,8$ or $16 \mathrm{~min}$. Temperatures which are greater than $58^{\circ} \mathrm{C}$ were also performed. (2) $p H$ effect. Each enzyme sample $(3 \mu \mathrm{g} / 12 \mu \mathrm{L})$ was adjusted to desired $\mathrm{pH}$ by adding a half volume of buffer with different pHs: $0.2 \mathrm{M}$ citrate buffer $(\mathrm{pH}$ 4.0), $0.2 \mathrm{M}$ phosphate buffer (pH 5.0, 6.0, 7.0, 8.0, or 9.0) or 0.2 M CAPS buffer $(\mathrm{pH}$ 10.0). Each sample was incubated at room temperature for $30 \mathrm{~min}$. At the end of each treatment, TcAAD enzyme activity were checked at $\mathrm{pH} 6.0$ in the 
presence NADPH or was subjected to $12 \%$ SDS-PAGE analysis as mentioned above.

\section{Results}

Cloning and characterization of a CDNA encoding TCAAD A putative TcAAD cDNA clone was identified on the basis of the consensus pattern and sequence homology to the published AADs in NCBI database. The entire coding region of TcAAD $\mathrm{CDNA}$ is $1,044 \mathrm{bp}$ long and the deduced protein consists of 348 amino acid residues with calculated molecular mass of $39.1 \mathrm{kDa}$ (GenBank no. HQ453361). Figure 1 shows the optimal alignment of the amino acid sequences of the TcAAD with 6 selected AAD sequences from other sources. This TcAAD shared 75\% identity with TvAAD (Trametes versicolor FP-101664 SS1, EIW61070), 72\% identity with CcAAD (Coprinopsis cinerea okayama7\#130, XP_002911316), 69\% identity with PsAAD (Punctularia strigosozonata HHB-11173 SS5, EIN04988), 65\% identity with ShAAD (Stereum hirsutum FP-91666 SS1, EIM87563), 61\% identity with CnAAD (Cryptococcus neoformans var. neoformans JEC21, XP_567886), and 29\% identity with CvAAD (Coriolus versicolor, AB070838). The protein belongs to the aldo-keto reductase (AKR) superfamily. The AKR superfamily is one of the three enzyme superfamilies that perform oxidoreduction on a wide variety of substrates (Hyndman et al., 2003). AKRs play an important role in the phase II detoxification of a large number of pharmaceuticals, drugs, and xenobiotics. The highly conserved $\mathrm{His}^{153}$ is the putative catalytic site (Figure 1A, triangle) (Ichinose et al., 2002) and along with another three highly conserved amino acid residues, Asp $^{62}$, Tyr $^{67}$, and Lys ${ }^{95}$ are the catalytic tetrad in the putative active site pocket (see discussion session for details). The secondary structure, predicted by SWISS-MODEL program, showed $10 \alpha$ helices and $14 \beta$ strands. The 3-D structural model superimposed with crystal structure of voltage-dependent potassium channels (PDB code:3EAU) (light yellow) via the SPDBV_4 program was shown using protein solid ribbon (Figure 1B).

\section{Expression and purification of the recombinant TCAAD}

The coding region of the TcAAD was amplified by PCR and subcloned into an expression vector, pYEX-S1, as described in the Materials and methods. Positive clones were verified by DNA sequence analysis. The recombinant TcAAD was expressed, and the proteins were analyzed by a $12 \%$ SDS-PAGE in the absence of reducing agent and without boiling (Figure 2). The recombinant TcAAD was expressed as a His6-tagged fusion protein and was purified by affinity chromatography with nickel chelating Sepharose. A major band with molecular mass of $\sim 39 \mathrm{kDa}$ (expected size of TcAAD monomer) was detected in Ni-NTA eluted fractions by SDS-PAGE
(Figure 2, lanes 8-9). The fractions contained pure protein were pooled and characterized further. Analysis of the TcAAD by MALDI-TOF confirms the presence of a single protein with molecular mass of $40.58 \mathrm{kDa}$ (containing His6-tag). This indicates that the enzyme is predominantly monomeric in nature. The yield of the purified His6-tagged TcAAD was $1 \mathrm{mg}$ from $250 \mathrm{~mL}$ of culture. Functional recombinant TcAAD was detected by enzyme activity assay as describe below.

\section{Kinetic studies of the purified TcAAD}

As shown in Figure 3, the Lineweaver-Burk plot of the velocity $(1 / \mathrm{V})$ against $1 /$ [veratraldehyde] gave the $K_{\mathrm{M}}=$ $0.25 \mathrm{mM}, \mathrm{V}_{\max }=0.014 \mathrm{mM} / \mathrm{min}$. The ability of TcAAD to oxidize other benzyl compounds was tested by monitoring the oxidation rate using 4 different alcohol compounds (benzyl alcohol, 3,4-dimethoxybenzyl alcohol, 2,4-dimethoxybenzyl alcohol and 4-(hydroxymethyl) benzoic acid ) via an increase in $A_{355}$ due to the reduction of $\mathrm{NAD}^{+}$. As shown in Table 1, 4-(hydroxymethyl) benzoic acid was the best substrate for TcAAD among the benzyl alcohols tested (substrate structures as shown in Figure 4).

\section{Characterization of the purified TCAAD}

The functional recombinant TcAAD enzyme expressed by yeast was shown to possess AAD activity by its ability to reduce veratraldehyde which is a benzyl aldehyde to its corresponding benzyl alcohol in the presence of $\mathrm{NADPH}$ at $\mathrm{pH}$ 6.0. In the reduction of veratraldehyde to its corresponding alcohol (3,4-dimethoxylbenzyl alcohol) at $\mathrm{pH} 6.0$ and in the presence of NADPH, the conversion of $\mathrm{NADPH}$ to $\mathrm{NADP}^{+}$is veratraldehyde concentration dependent. And the data were used for double-reciprocal plot. Under the same experimental conditions when $\mathrm{NADPH}$ was replaced with $\mathrm{NADH}$, no enzyme activity was observed even when the substrate concentration of veratraldehyde was increased.

When benzyl alcohol; 2,4-dimethoxybenzyl alcohol; 3,4-dimethoxybenzyl alcohol and 4-(hydroxymethyl) benzoic acid were used as substrates to assay TcADD enzyme activity in the presence of $\mathrm{NADP}^{+}$at $\mathrm{pH}$ 9.6, no enzyme activity was detected even when the substrate concentration increased. However, under the same reaction conditions when $\mathrm{NADP}^{+}$was replaced with $\mathrm{NAD}^{+}$, TcADD enzyme activity was detected.

The recombinant TcAAD enzyme expressed by yeast was shown to possess AAD activity by its ability not only to reduce benzyl aldehyde via NADPH at $\mathrm{pH} 6.0$ but also to oxidize benzyl alcohol via $\mathrm{NAD}^{+}$at $\mathrm{pH}$ 9.6. It is interesting to note that reduction of benzyl aldehyde by the TcAAD at $\mathrm{pH} 6.0$ is NADPH-dependent while $\mathrm{NADH}$ did not yield detectable activity under the same conditions (results not shown). Oxidation of benzyl 

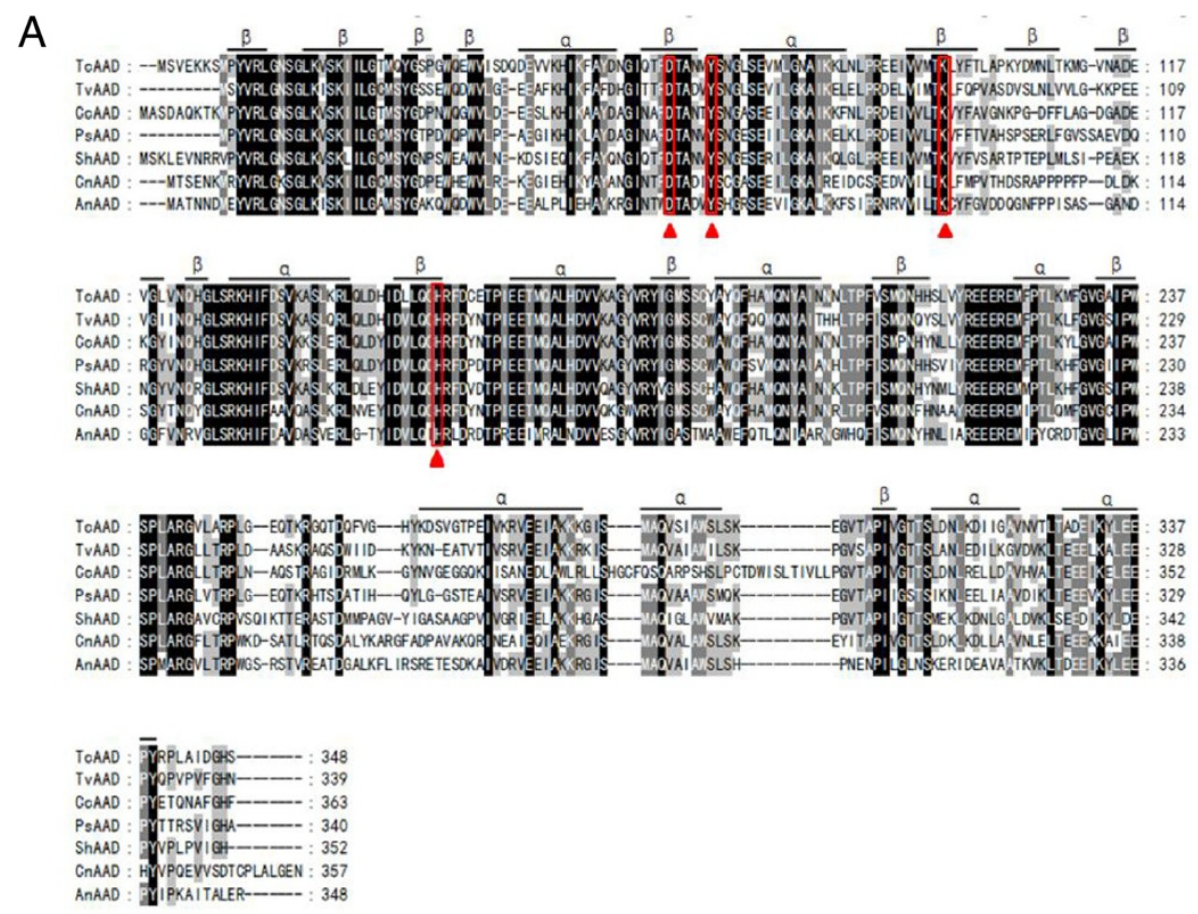

$\mathrm{B}$

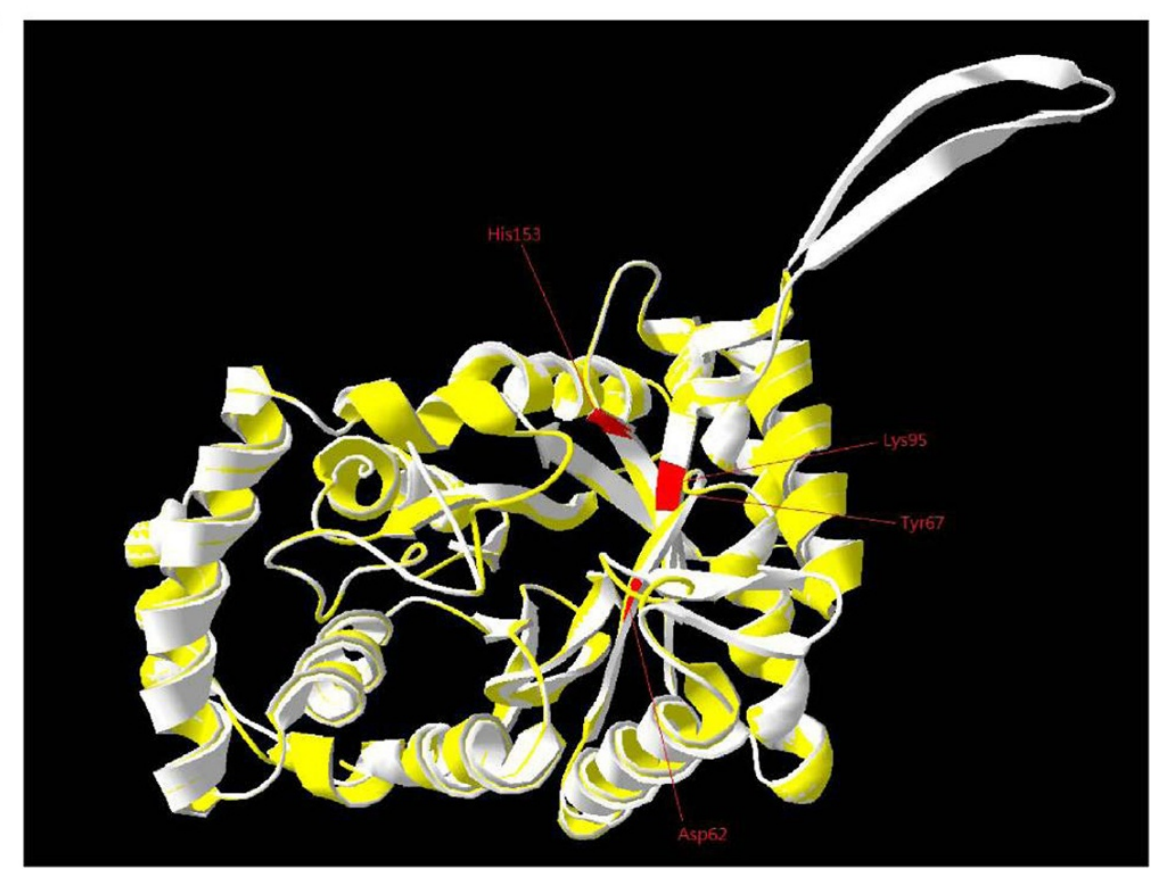

Figure 1 Alignment of the amino acid sequences of TCAAD with other organism's AADs, and its predicted 3-D structure. (A) Sequence alignment: TCAAD (this study), TVAAD (Trametes versicolor FP-101664 SS1, EIW61070), CCAAD (Coprinopsis cinerea okayama7\#130, XP_002911316), PsAAD (Punctularia strigosozonata HHB-11173 SS5, EIN04988), ShAAD (Stereum hirsutum FP-91666 SS1, EIM87563), CnAAD (Cryptococcus neoformans var. neoformans JEC21, XP_567886), CVAAD (Coriolus versicolor, AB070838). Protein secondary structure was predicted by SWISS-MODEL program and represented as $a$-helices and $\beta$-strands. The triangle indicates putative active site. (B) The structural model of TCAAD was predicted based on the known crystal structure of a shaker family voltage-dependent potassium channels (Kv1) subunit beta-2 from Rattus norvegicus (PDB code: 3EAU) via SWISS-MODEL program. TCAAD (light white) and template (light yellow, PDB code: 3EAU) was shown using protein solid ribbons. TCADD belongs to the aldo-keto-reductases superfamily with catalytic tetrad, Asp ${ }^{62}$, Tyr ${ }^{67}$, Lys ${ }^{95}$, and His ${ }^{153}$, which are conserved as they are present in almost all members of the superfamily (NCBI AKR superfamily conserved domain search). His ${ }^{153}$ is one of the catalytic tetrad and is the putative active site. 


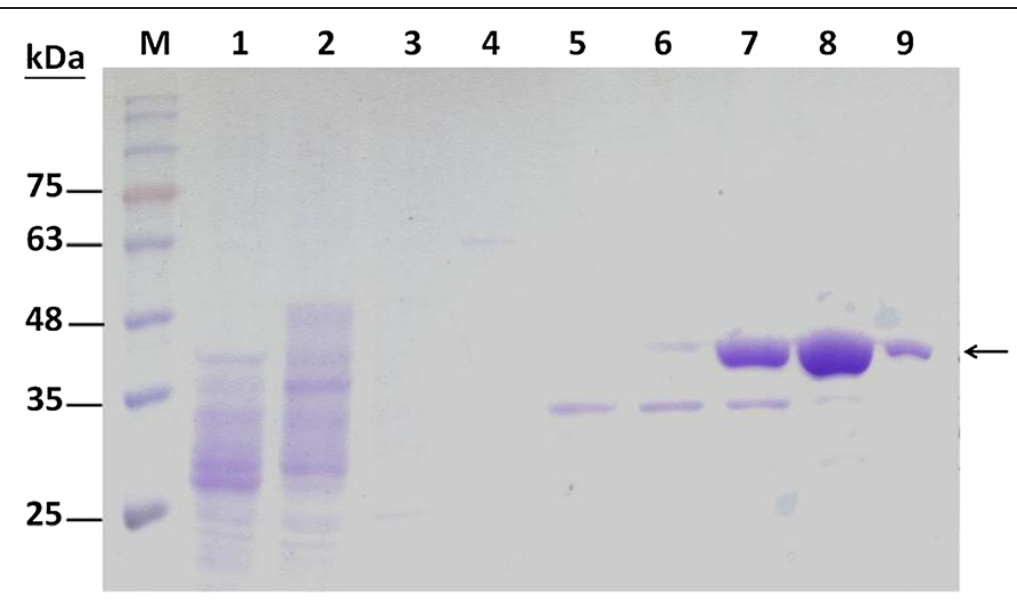

Figure 2 Expression and purification of recombinant TcAAD in Saccharomyces cerevisiae. Fifteen $\mu \mathrm{L}$ of each fraction was loaded into each lane of the 12\% SDS-PAGE followed by Coomassie Brilliant Blue R-250 staining. Lane 1, crude extract from Saccharomyces cerevisiae expressing TCAAD; 2, flow-through proteins from the Ni-NTA column; 3-9, TCAAD eluted from Ni-NTA column. Molecular masses (in kDa) of standards are shown at left.

alcohol by the TcAAD at $\mathrm{pH} 9.6$ is $\mathrm{NAD}^{+}$-dependent (Table 1) while $\mathrm{NADP}^{+}$did not yield detectable activity under the same conditions (results not shown).

Heat stability of the TcAAD was tested to examine the effect of heat on the AAD activity, the purified TcAAD was heat-treated at $58^{\circ} \mathrm{C}$ for various time followed by TcAAD enzyme activity assay as described in "Materials and methods". The TcAAD's half-life of deactivation at $58^{\circ} \mathrm{C}$ was $4.2 \mathrm{~min}$, and its thermal inactivation rate constant $k_{\mathrm{d}}$ was $7.4 \times 10^{-2} \mathrm{~min}^{-1}$ (Figure 5). There was no detectable TcADD enzyme activity when it was heated above $60^{\circ} \mathrm{C}$.

With regard toTcAAD enzyme activity at different $\mathrm{pH}$, the optimal activity to convert veratraldehyde to its corresponding 3,4-dimethoxybenzyl alcohol was observed at $\mathrm{pH}$ 6.0. As $\mathrm{pH}$ increased to $\mathrm{pH} 8$ and 10, the enzyme

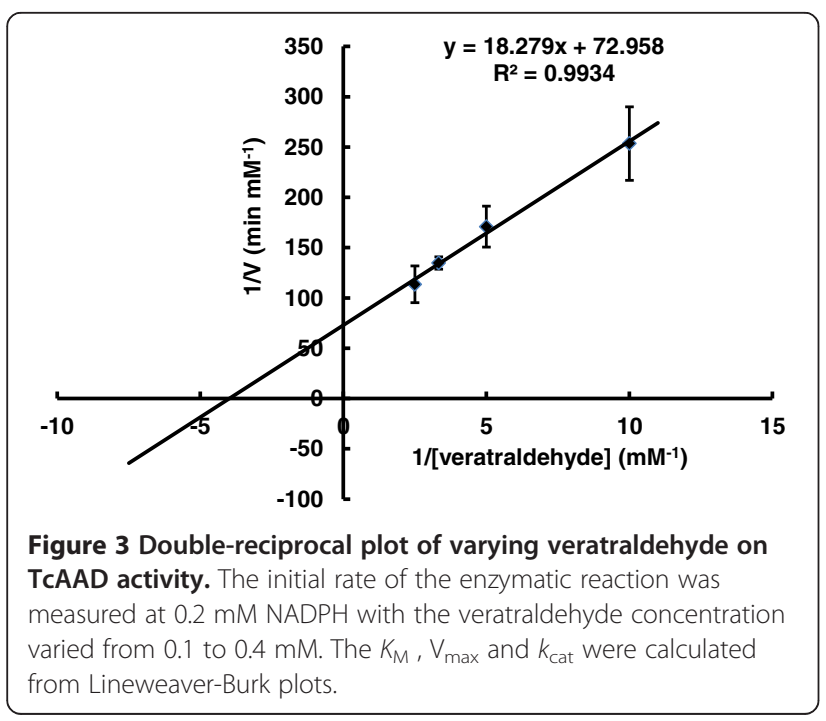

retained $62 \%$ activity; and the enzyme retained $13 \%$ activity at $\mathrm{pH} 4$ (Figure 6).

\section{Discussion and conclusions}

This is the first report of TcAAD from T. camphorata, including the cloning, expression and purification of the functional recombinant enzyme from Saccharomyces cerevisiae for biochemical characterizations. The TcAAD enzyme behaves differently from other known AADs (discussed in the next paragraph) in the cofactors used. The enzyme can catalyze conversion of veratraldehyde to its corresponding benzyl alcohol (3,4-dimethoxybenzyl alcohol) at various $\mathrm{pH}$ from 4-10, with the optimal $\mathrm{pH}$ of 6.0 (Figure 6) and used NADPH as cofactor. When using $\mathrm{NAD}^{+}$as cofactor at the optimal $\mathrm{pH}$ of 9.6, it can aslo catalyze the conversion of benzyl alcohols (benzyl alcohol; 2,4-dimethoxybenzyl alcohol; 3,4-dimethoxybenzyl alcohol; and 4-(hydroxymethyl) benzoic acid) to its corresponding benzylaldehydes (no activity was detected when $\mathrm{NADP}^{+}$was used). Thus, as shown in Table 1 and Figure 6, the TcAAD's optimal $\mathrm{pH}$ is at 6 . It is possible that in T. camphorata's the TcAAD functions in the reductive state using NADPH as cofactor.

Several NAD $(\mathrm{P})^{+} / \mathrm{NAD}(\mathrm{P}) \mathrm{H}$-dependent AAD enzymes from various bacterial \& fungal sources have been reported: a) $\mathrm{NAD}^{+}$-dependent AAD enzyme from Pseudomonas putida was reported to oxidize benzyl alcohol derivatives (including 4-methoxybenzyl alcohol) to their corresponding benzylaldehydes at $\mathrm{pH} 9.6$ (Siljegovic et al., 1998). b) NADPH-dependent AAD enzyme from Pleurotus eryngii was able to reduce benzylaldehyde derivatives (including veratraldehyde) to their corresponding benzyl alchhols at pH 6.0 (Guillen and Evans, 1994). 
Table 1 Summary of the reactions catalyzed by TCAAD

\begin{tabular}{llll}
\hline Substrate & Cofactor & Product & V (nmole of NADH/min/mg of TcAAD) \\
\hline benzyl alcohol & $\mathrm{NAD}^{+}$ & benzyl aldehyde & $262.72 \pm 13.15$ at $\mathrm{pH} 9.6$ \\
3,4-dimethoxybenzyl alcohol & $\mathrm{NAD}^{+}$ & veratraldehyde & $290.05 \pm 13.15$ at $\mathrm{pH} 9.6$ \\
2,4-dimethoxybenzyl alcohol & $\mathrm{NAD}^{+}$ & 2,4-dimethoxybenzyl aldehyde & $232.35 \pm 12.05$ at $\mathrm{pH} 9.6$ \\
4-(hydroxymethyl)benzoic acid & $\mathrm{NAD}^{+}$ & & $1099.47 \pm 17.05 \mathrm{at} \mathrm{pH} 9.6$ \\
4-(hydroxymethyl)benzoic acid & $\mathrm{NADP}$ & No reaction at pH 9.6 \\
veratraldehyde & $\mathrm{NADH}$ & 3,4-dimethoxybenzyl alcohol & No reaction at $\mathrm{pH} 6$ \\
veratraldehyde & $\mathrm{NADPH}$ & 3,4-dimethoxybenzyl alcohol & $\mathrm{V}_{\max }=0.014 \mathrm{mM} / \mathrm{min}$ at $\mathrm{pH} 6$ \\
\hline
\end{tabular}

Enzymatic activity $(\mathrm{V} \pm \mathrm{SD})$ was measured as described in Materials and Methods in the presence of $10 \mu \mathrm{g} / 0.1 \mathrm{~mL}$ enzyme, $4 \mathrm{mM} \mathrm{NAD}{ }^{+}, 0.1 \mathrm{mM}$ alcohol related substrates at $\mathrm{pH}$ 9.6. The $\mathrm{V}$ was measured as the increase of $\mathrm{NADH}(355 \mathrm{~nm})$ in the first $0.5-1$ min reaction at $25^{\circ} \mathrm{C}$. The reactions with veratraldehyde substrate were carried out in the presence of $3 \mu \mathrm{g} / 0.1 \mathrm{~mL}$ enzyme, $0.2 \mathrm{mM} \mathrm{NADH}$ or $0.2 \mathrm{mM} \mathrm{NADPH}$ and $0.2 \mathrm{mM}$ veratraldehyde at pH 6 . The $\mathrm{V}$ was measured as the decrease of $\mathrm{NADH}(355 \mathrm{~nm})$ or NADPH $(365 \mathrm{~nm})$ in the first $0.5-1$ min reaction at $25^{\circ} \mathrm{C}$.

c) NAD $(\mathrm{P}) \mathrm{H}$-dependent benzyl alcohol dehydrogenase activity was also reported from Lactobacillus plantarum WCFS1. This enzyme is more active in the presence of $\mathrm{NAD}^{+}$than $\mathrm{NADP}^{+}$in oxidizing benzyl alcohol, nerol, geraniol, phenethyl alcohol, cinnamyl alcohol, and coniferyl alcohol with optimal $\mathrm{pH}$ of 5.0 (Landete et al., 2008). d) Aryl-alcohol dehydrogenase from the white-rot fungus Phanerochaete chrysosporium strain BKM-F-1767 is more active in the presence of NADPH $\left(K_{\mathrm{M}}\right.$ is $\left.39 \mu \mathrm{M}\right)$ than $\mathrm{NADH}\left(K_{\mathrm{M}}\right.$ is $\left.220 \mu \mathrm{M}\right)$ in reducing benzylaldehyde to benzyl alcohol (Yang et al., 2012). All the assay conditions for AADs activity have something in common. The reduction reactions were carried out at $\mathrm{pH} 6.0$ with substrate concentration of benzylaldehyde in the range of 0.2-0.4 $\mathrm{mM}$ and enzyme amount about $3 \mu \mathrm{g}$, while higher concentrations of substrate of benzyl alcohols

\begin{tabular}{|l|l|}
\hline Substrate name & Substrate structure \\
\hline 4-(hydroxymethyl)benzoic acid & 2,4-dimethoxybenzyl alcohol \\
\hline 3,4-dimethoxybenzaldehyde \\
(veratraldehyde) \\
3,4-dimethoxybenzyl
\end{tabular}




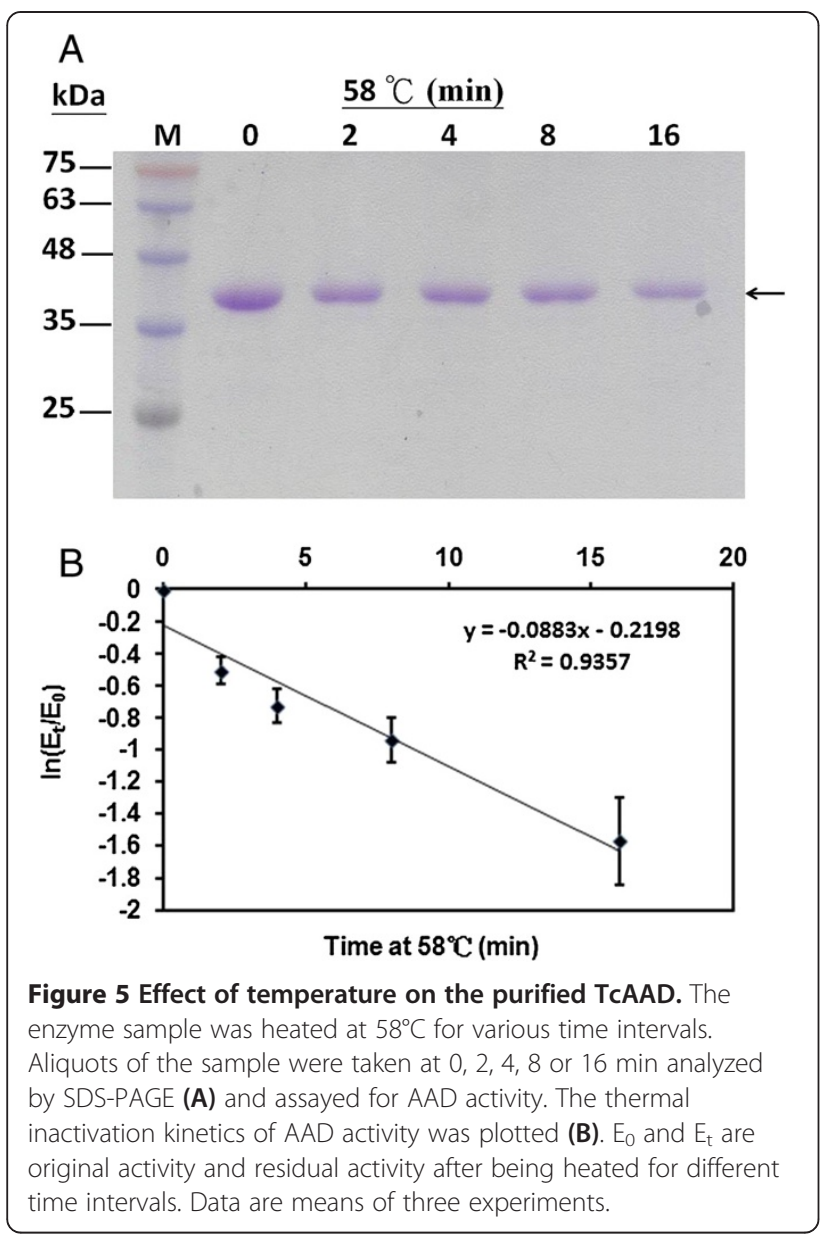

(4-5 $\mathrm{mM})$ and enzyme amount $(\sim 10 \mu \mathrm{g})$ were used for the oxidation reactions at $\mathrm{pH} 9.6$ (except for the Lactobacillus plantarum at $\mathrm{pH}$ 5.0). The substrate concentrations and the amount of TcAAD used in our enzyme-catalyzed assays were in the same range.

It is unclear why the TcADD uses different cofactors for the oxidation reactions $\left(\mathrm{NAD}^{+}\right)$and reduction reactions $(\mathrm{NADPH})$ of substrates. In literature, structures of a large number of $\mathrm{NAD}^{+}$-binding enzymes have been studied and compared. It was concluded that these enzymes possess a similar structure with a $\beta-\alpha-\beta$ fold characteristic of nucleotide binding proteins (Schade et al., 1990). The analysis revealed a consensus sequence for the $\mathrm{NAD}^{+}$-binding dinucleotide fold (GXGXXG) which locates between the first $\beta$-strand and the $\alpha$-helix allowing the formation of a tight turn (Wierenga et al., 1986). Other analysis revealed a consensus sequence for the $\mathrm{NADP}^{+}$-binding dinucleotide fold (GXGXXAXXXAXXXXXXG) (Hanukoglu and Gutfinger, 1989). A search for $\mathrm{NAD}^{+}$and $\mathrm{NADP}^{+}$-binding dinucleotide folds within the protein sequence of TcADD, we found conserved putative binding motifs for both. A putative $\mathrm{NAD}^{+}$-binding dinucleotide fold was found at positions 231-235 with the sequence GVGAI, and a putative $\mathrm{NADP}^{+}$-binding dinucleotide fold was found at positions 231-250 with the sequence GVGAIPWSPLARGVLARPLG.

Protein multiple sequence alignment indicated that TcAAD is a member of the NADP ${ }^{+}$-dependent aldoketo reductases (AKRs) superfamily having conserved domain with typical catalytic tetrad (four highly conserved amino acid residues, Asp, Tyr, Lys and His

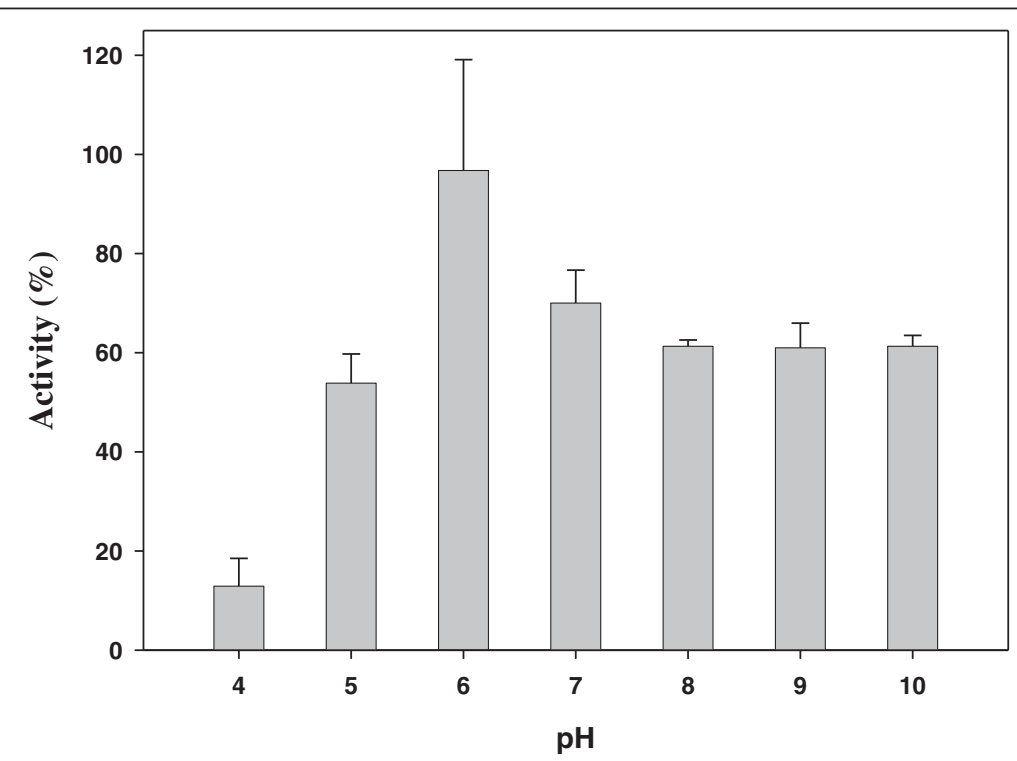

Figure 6 Effect of pH on the purified TcAAD. The enzyme samples were incubated with different pH buffer at $37^{\circ} \mathrm{C}$ for 30 min and then assayed for AAD activity. Data are means \pm S.D. of three similar experiments. 
interact with the substrate and $\mathrm{NADP}^{+}$). Indeed, the catalytic tetrad, $\mathrm{Asp}^{62}$, $\mathrm{Tyr}^{67}$, $\mathrm{Lys}^{95}$, and $\mathrm{His}^{153}$ are present in the TcAAD sequence. Regardless that members of the AKRs superfamily have different 3-D structures, they have a common conserved domain consisted of 8 parallel $\beta$-strands in the center surrounded by $8 \alpha$-helices to form a $(\alpha \beta)_{8}$-barrel which contains a $\mathrm{NADP}^{+}$-binding motif (NCBI AKRs superfamily conserved domain search. http://www.ncbi.nlm.nih.gov/Structure/cdd/ wrpsb.cgi). The domain structure is arranged in that the nicotinamide-binding half ( 3 parallel $\beta$-strands and $2 \alpha$ helices) is structurally similar to the adenine-binding half (another 3 parallel $\beta$-strands and $2 \alpha$-helices) to form a Rossmann fold for $\mathrm{NADP}^{+}$-binding.

Using the conserved domain search tool, we found a total of 25 conserved residues in the putative active site pocket of the TcAAD, including the catalytic tetrad. These residues are $\mathrm{Gly}^{26}, \mathrm{Thr}^{27}, \mathrm{Met}^{28}, \mathrm{Asp}^{62}, \mathrm{Tyr}^{67}$, $\mathrm{Lys}^{95}, \mathrm{His}^{153}, \operatorname{Arg}^{154}, \mathrm{Ser}^{183}, \mathrm{Ser}^{184}, \mathrm{Gln}^{209}, \operatorname{Trp}^{237}$, $\mathrm{Ser}^{238}, \mathrm{Pro}^{239}, \mathrm{Leu}^{240}, \mathrm{Ala}^{241}, \mathrm{Arg}^{242}, \mathrm{Ala}^{290}, \mathrm{Ile}^{307}$, $\mathrm{Val}^{308}, \mathrm{Gly}^{309}, \mathrm{Thr}^{310}, \mathrm{Asn}^{315}, \mathrm{Asp}^{318}$, and $\mathrm{Ile}^{319}$.

TcAAD is a member of the aldo-keto reductases superfamily which prefers NADPH over NADH (Barski et al., 2008). Therefore, it is logical to explain the requirement of NADPH of TcAAD to catalyze reduction reactions at $\mathrm{pH}$ 6.0. However we can't explain its novelty in which the enzyme does not utilize $\mathrm{NADP}^{+}$to oxidize its substrates at $\mathrm{pH}$ 9.6, instead $\mathrm{NAD}^{+}$was used. It has been reported that the active site pocket of aldose reductases is hydrophobic in nature and favors aromatic and nonpolar substrates over polar ones (Wilson et al., 1992). However, contradict to the above statement; the active site pocket of TCAAD contains more polar or charged residues under physiological condition (15 out of 25 amino acid residues). Maybe at $\mathrm{pH}$ 9.6, TcAAD exists in a conformation favors $\mathrm{NAD}^{+}$over $\mathrm{NADP}^{+}$. At $\mathrm{pH}$ 6, TcAAD exists in another conformation favors NADPH over NADH.

The TcAAD may be considered in the design of metabolic engineering strategies/synthetic biology systems for biotechnological applications. For instance, TcADD can be used to degrade aromatic inhibitors that are present in lignocellulosic hydrolysates which will otherwise impair yeast fermentation (Almeida et al., 2007). Additionally, the enzyme may be used in production of natural flavors and fragrances such as the rose-like flavor compound 2-Phenylethanol (Yang et al., 2012).

\section{Abbreviations}

AAD: Aryl-alcohol dehydrogenases; SDS-PAGE: Sodium dodecyl sulfate-polyacrylamide gel electrophoresis; PBS: Phosphate buffer saline.

\section{Competing interest}

The authors declare that they have no competing interests.

\section{Authors' contributions}

C-FK and C-CC carried out the molecular genetic studies and biochemical studies. C-TL was an adviser to carry out the molecular genetic and biochemical studies. LW and J-KH participated in drafting the manuscript. C-TL, LW and J-KH drafted the manuscript and revised the manuscript.

All authors read and approved the final manuscript.

\section{Acknowledgements}

This work was supported by the National Science Council of the Republic of China, Taiwan under grant 100-2313-B-019-003-MY3 to C-T. Lin.

\section{Author details}

${ }^{1}$ Institute of Bioscience and Biotechnology and Center of Excellence for the Oceans, National Taiwan Ocean University, 2 Pei-Ning Road, Keelung 202, Taiwan. ${ }^{2}$ Institute of Biotechnology, National Changhua University of Education, Changhua, Taiwan. ${ }^{3}$ Department of Chemistry, Western Illinois University, 1 University Cir, Macomb, IL 61455, US.

Received: 2 November 2013 Accepted: 22 January 2014 Published: 2 February 2014

\section{References}

Almeida JR, Modig T, Petersson A, Hähn-Hägerdal B, Lidén G, Gorwa-Grauslund MF (2007) Increased tolerance and conversion of inhibitors in lignocellulosic hydrolysates by Saccharomyces cerevisiae. J Chem Technol Biotechnol 82:340-349

Ao ZH, Xu ZH, Lu ZM, Xu HY, Zhang XM, Dou WF (2009) Niuchangchih (Antrodia camphorata) and its potential in treating liver diseases. J Ethnopharmacol 121:194-212

Arnold K, Bordoli L, Kopp J, Schwede T (2006) The SWISS-MODEL workspace: a web-based environment for protein structure homology modeling. Bioinformatics 22:195-201

Barski OA, Tipparaju SM, Bhatnagar A (2008) The aldo-keto reductase superfamily and its role in drug metabolism and detoxification. Drug Metab Rev 40:553-624

Bradford MM (1976) Rapid and sensitive method for the quantitation of microgram quantities of protein utilizing the principle of protein-dye binding. Anal Biochem 72:248-254

Guillen F, Evans CS (1994) Anisaldehyde and veratraldehyde acting as redox cycling agents for $\mathrm{H}_{2} \mathrm{O}_{2}$ production by pleurotus eryngii. Appl Environ Microbiol 60:2811-2817

Hanukoglu I, Gutfinger T (1989) CDNA sequence of adrenodoxin reductase, identification of NADP-binding sites in oxidoreductases. Eur J Biochem 180:479-484

Hsieh YH, Chu FH, Wang YS, Chien SC, Chang ST, Shaw JF, Chen CY, Hsiao WW, Kuo YH, Wang SY (2010) Antrocamphin A, an anti-inflammatory principal from the fruiting body of Taiwanofungus camphoratus, and its mechanisms. J Agric Food Chem 58:3153-3158

Huang CY, Ken CF, Wen L, Lin CT (2009) An enzyme possessing both gluthathione-dependent formaldehyde dehydrogenase and $\mathrm{S}$-nitrosogluthathione reductase from Antrodia camphorata. Food Chem 112:795-802

Hyndman D, Bauman DR, Heredia W, Penning TM (2003) The aldo-keto reductase superfamily homepage. Chem-Biol Interact 143-144:621-631

Ichinose H, Wariishi H, Tanaka H (1999) Bioconversion of recalcitrant 4-methyldibenzothiopheneto water-extractable products using lignin-degrading basidiomycete Coriolus versicolor. Biothechnol Prog 15:706-714

Ichinose H, Wariishi H, Tanaka H (2002) Molecular analysis of arylalcohol dehydrogenase of Coriolus versicolor expressed against exogenous addition of dibenzothiophene derivatives. J Basic Microbiol 42:327-336

Jensen KA, Evans KMC, Kirk TK, Hammei KE (1994) Biosynthetic pathway for veratryl alcohol in the ligninolytic fungus Phanerochaete chrysosporium. Appl Environ Microbiol 60:709-714

Ken CF, Hsiung TM, Huang ZX, Juang RH, Lin CT (2006) Characterization of Fe/Mn-superoxide dismutase from diatom Thallassiosira weissflogii: cloning, expression, and property. J Agric Food Chem 53:1470-1474

Ken CF, Chen HT, Chang RC, Lin CT (2008) Biochemical characterization of a catalase from Antrodia camphorata: expression in Escherichia coli and enzyme properties. Bot Stud 49:119-125 
Ken CF, Lin CY, Jiang YC, Wen L, Lin CT (2009) Cloning, expression and characterization of an enzyme possesses both glutaredoxin and dehydroascorbate reductase activity from Taiwanofungus camphorata J Agric Food Chem 57:10357-10362

Ken CF, Chen IJ, Lin CT, Liu SM, Wen L, Lin CT (2011) A monothiol glutaredoxin cDNA from Taiwanofungus camphorata: a novel CGFS-type glutaredoxin possessing glutathione reductase activity. J Agric Food Chem 59:3828-3835

Landete JM, Rodríguez H, de Las RB, Muñoz R (2008) Characterization of a benzyl alcohol dehydrogenase from Lactobacillus plantarum WCFS1. J Agric Food Chem 56:4497-4503

Liau YJ, Wen L, Shaw JF, Lin CT (2007) A highly stable cambialistic-superoxide dismutase from Antrodia camphorata: expression in yeast and enzyme properties. J Biotechnol 131:84-91

Liau YJ, Chen YT, Lin CY, Huang JK, Lin CT (2010) Characterization of 2-Cys peroxiredoxin isozyme (Prx1) from Taiwanofungus camphorata (Niu-chang-chih): expression and enzyme properties. Food Chem 119:154-160

Muheim A, Waldner R, Sanglard D, Reiser J, Schoemarker HE, Leisola SA (1991) Purification and properties of an aryl-alcohol dehydrogenase from the white-rot fungus Phanerochaete chrysosporium. Eur J Biochem 195:369-375

Schade SZ, Early SL, Williams TR, Kézdy FJ, Heinrikson RL, Grimshaw CE (1990) Sequence analysis of bovine lens aldose reductase. J Biol Chem 265:3628-3635

Siljegovic V, Boschetti A, Spichiger UE, Guggisberg D, Koch HA (1998) NAD ${ }^{+} / \mathrm{NADH}$-dependent dehydrogenase from Pseudomonas putida acting on salbutamol. Biotechnol Lett 20:667-671

Wen L, Huang HM, Juang RH, Lin CT (2007) Biochemical characterization of 1-Cys peroxiredoxin from Antrodia camphorata. Appl Microbiol Biotechnol 73:1314-1322

Wierenga RK, Terpstra P, Hol WGJ (1986) Prediction of the occurrence of the ADP-binding $\beta a \beta$-fold in proteins, using an amino acid sequence fingerprint. J Mol Biol 187:101-107

Wilson DK, Bohren KM, Gabbay KH, Quiocho FA (1992) An unlikely sugar substrate site in the $1.65 \AA$ structure of the human aldose reductase holoenzyme implicated in diabetic complications. Science 257:81-84

Yang DD, François JM, de Billerbeck GM (2012) Cloning, expression and characterization of an aryl-alcohol dehydrogenase from the white-rot fungus Phanerochaete chrysosporium strain BKM-F-1767. BMC Microbiol 12:126

doi:10.1186/1999-3110-55-14

Cite this article as: Ken et al: Biochemical characterization of a functional recombinant aryl-alcohol dehydrogenase from Taiwanofungus camphorata. Botanical Studies 2014 55:14.

\section{Submit your manuscript to a SpringerOpen ${ }^{\odot}$ journal and benefit from:}

- Convenient online submission

- Rigorous peer review

- Immediate publication on acceptance

- Open access: articles freely available online

- High visibility within the field

- Retaining the copyright to your article

Submit your next manuscript at $\gg$ springeropen.com 